\title{
The behaviour of extended duties dental nurses and the acceptance of fluoride varnish application in preschool children
}

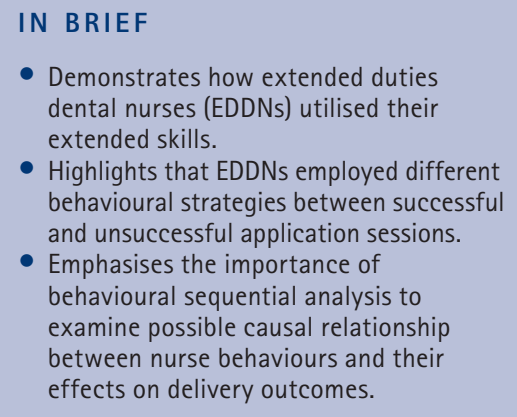

\author{
Y. Zhou, ${ }^{1}$ G. M. Forbes, ${ }^{2}$ L. M. D. Macpherson, ${ }^{3}$ G. E. Ball ${ }^{4}$ \\ and G. M. Humphris ${ }^{5}$
}

VERIFIABLE CPD PAPER

Background Extended duties dental nurses (EDDNs) have been trained to deliver fluoride varnish applications to preschool children as part of the Childsmile initiative in Scotland. Objectives To determine a detailed behavioural profile of the EDDNs during the administration of the fluoride varnish to confirm professional manner and identify differences in nurse behaviours between successful and unsuccessful application sessions. Methods Nurse-child interactions were video recorded and nurse behaviours coded and analysed using a specially developed coding scheme (SABICS). Behaviour frequency and duration were measured and correlations were calculated. Differences in behaviour were examined between successful and unsuccessful application sessions. Results Three hundred and three interactions were coded out of 456 recorded application sessions. No incident occurred where nurses threatened or placed undue stress on a child. In unsuccessful, compared with successful, application sessions, nurses demonstrated higher frequency and duration of the following behaviours: 'permission seeking', 'offer of task alternative', 'information seeking' and 'reassurance', controlling for length of procedure. Whereas with successful applications, 'praise', 'instruction' and 'information-giving' were used more frequently and for a longer duration, compared with unsuccessful applications. Conclusions The EDDNs demonstrated a professional manner working with preschool children. They behaved differently between successful and unsuccessful application sessions. Sequential analysis is needed to examine causal effects of behaviours and its effects on delivery outcomes.

\section{INTRODUCTION}

The fluoride varnish application, a dental preventive intervention, has some positive benefits for reducing caries in preschool children. ${ }^{1}$ It is an important part of a National Health Service (NHS) initiative to improve the oral health of children in Scotland known as Childsmile., ${ }^{2,3}$ The General Dental Council (GDC) has allowed dental nurses to develop additional skills to undertake fluoride varnish applications under the GDC Scope of practice guidance. ${ }^{4,5}$ The guidance stresses that the application of fluoride varnish by a dental nurse must be part of a programme which is overseen by a consultant in dental public health or a registered specialist

\footnotetext{
1;2,5School of Medicine, University of St Andrews; ${ }^{3}$ Community Oral Health Section, University of Glasgow Dental School; ${ }^{4}$ Department of Dental Public Health, NHS Fife

${ }^{*}$ Correspondence to: Dr Zhou

Email address:yz10@st-andrews.ac.uk;

Tel.: +44 1334 463564; fax: +441334467470
}

\section{Refereed Paper}

Accepted 29 October 2012

DOI: 10.1038/sj.bdj.2012.1133

${ }^{\circ}$ British Dental Journal 2012; 213: 603-609 in dental public health. This guidance has provided an opportunity for dental nurses to have much more direct involvement in preventive procedures. The Childsmile programme employs dental nurses to apply fluoride varnish onto the teeth of preschool children as part of a range of preventive interventions. In this role they are known as extended duties dental nurses (EDDNs). In response to this significant change in dental professional practice, there have been a small number of studies exploring the extent to which the EDDNs utilise their extended skills in their direct involvement with patient care. ${ }^{6,7}$ In a recent survey, the impact of a fluoride application training course on EDDNs' professional career was reported. ${ }^{7}$ So far, no study has explored the behavioural aspects of the EDDNs while they are undertaking preventive dental practice using an observational method.

Since the launch of Childsmile in 2006 in Scotland, the programme is proving successful in that it has delivered a substantial number of applications. The absolute number of nursery-school children receiving at least one fluoride varnish application has reached 21,614 in 2010-2011 nurseryschool year. ${ }^{8}$ However, our pilot data suggests that approximately $10 \%$ of children who were signed onto the Childsmile programme failed to receive the application, or did not receive the full application on the day of nursery school visit. Hence, an important question arises: is there a particular set of features in the nurse-child interaction that might affect the application outcome? Given the practical challenge of improving the acceptability of the fluoride application, it was considered important to conduct an investigation into the relationship between the behavioural interaction during the delivery process and the delivery outcome. The Childsmile programme has an integral evaluation component. It commissioned the University of St Andrews to focus on the behavioural aspects of the delivery of the fluoride varnish element of its programme named Childsmile Nursery. In this programme, the EDDNs work in pairs, with one nurse taking the lead role of applying the fluoride varnish onto the teeth of 3-5-yearold children at nursery schools and the 
other nurse providing equipment. The two nurses exchanged their roles to share the intensity of their workload.

Research in healthcare communication has consistently demonstrated that effective communication enhances healthcare outcomes. ${ }^{9}$ When young children are involved, research evidence suggests that certain dental staff behaviours that occur during routine clinical practice have positive effects in improving child cooperation. ${ }^{10}$ We are, therefore, interested in investigating verbal and non-verbal behaviours EDDNs used to encourage cooperative behaviours of children in receiving the fluoride varnish application. This approach may help broadly understand the influence of the training programme designed for EDDNs to conduct themselves professionally and communicate effectively, and specifically indicate how acceptability might be improved through behavioural management.

Specific research questions for the current study are as follows:

1. What is the detailed behavioural profile of EDDNs during the administration of the fluoride varnish?

2. Is there evidence to show that EDDNs acted in a professional manner outlined in the GDC standards guidance $^{5}$ during the procedure?

3. Do dental nurses behave differently between successful and unsuccessful application sessions?

4. If so, what types of nurse behaviours are associated with both successful and unsuccessful applications?

\section{METHODS}

\section{Study design}

A cross-sectional observational study was conducted with video observation of nurse-child interaction during the fluoride varnish application at nursery school settings across three NHS health boards in Scotland. Video observation was a superior method to capture both verbal and nonverbal behaviours of communication to address the research questions. A possible bias in data collection was that participant behaviours might be affected by the presence of the video camera and recording. Empirical evidence from our own observations and elsewhere ${ }^{11,12}$ provided some reassurance that studying healthcare

\begin{tabular}{|c|c|c|c|c|}
\hline Category & Sample & Consent rate & Participation rate & Health board* \\
\hline School & 36 & 35 (97\%) & 35 (100\%) & $\begin{array}{l}\text { HB-A } 16 \\
\text { HB-B } 14 \\
\text { HB-C } 5\end{array}$ \\
\hline Dental nurse & 21 & 21 (100\%) & 21 (100\%) & $\begin{array}{l}\text { HB-A } 7 \\
\text { HB-B } 8 \\
\text { HB-C } 6\end{array}$ \\
\hline $\begin{array}{l}\text { Children } \\
\text { (parent consents) }\end{array}$ & 1614 & 509 (32\%) & 456 (90\%) & $\begin{array}{l}\text { HB-A } 212 \\
\text { HB-B } 163 \\
\text { HB-C } 81\end{array}$ \\
\hline
\end{tabular}

Table 2 Summary of demographic information

\begin{tabular}{|c|c|c|c|c|}
\hline Variables & & $\begin{array}{l}\text { Recorded children } \\
(n=456)\end{array}$ & $\begin{array}{l}\text { Coded children } \\
(n=303)\end{array}$ & Comparability test \\
\hline \multirow[t]{3}{*}{ Application outcome } & refusal & 27 (5.9\%) & $24^{*}(7.9 \%)$ & $\mathrm{N} / \mathrm{A}$ \\
\hline & partial & $7(1.6 \%)$ & $7(2.3 \%)$ & \\
\hline & success & $422(92.5 \%)$ & $272(89.8 \%)$ & \\
\hline \multirow[t]{2}{*}{ Problem teeth** } & yes & $63(13.8 \%)$ & $41(13.5 \%)$ & $X^{2}(1)=0.001$ \\
\hline & no & 393 (86.2\%) & $262(86.5 \%)$ & $p=0.997$ \\
\hline \multirow[t]{3}{*}{ Age (in months) } & & Mean $=50.2$ & Mean $=49.35$ & $t(755)=1.67$ \\
\hline & & Mode $=49(n=454)$ & Mode $=49$ & $p=0.096$ \\
\hline & & $S D=6.91$ & $S D=6.84$ & \\
\hline \multirow[t]{2}{*}{ Gender } & boy & $227(49.8 \%)$ & $152(50.2 \%)$ & $X^{2}(2)=0.001$ \\
\hline & girl & $229(50.2 \%)$ & $151(49.8 \%)$ & $p=0.976$ \\
\hline \multirow[t]{3}{*}{ Health board area } & HB-A & $212(46.5 \%)$ & $138(45.5 \%)$ & $X^{2}(1)=0.067$ \\
\hline & HB-B & $163(35.7 \%)$ & $110(36.3 \%)$ & $p=0.967$ \\
\hline & $\mathrm{HB}-\mathrm{C}$ & $81(17.8 \%)$ & $55(18.2 \%)$ & \\
\hline \multirow[t]{2}{*}{ First time application } & yes & $72(15.8 \%)$ & $72(23.8 \%)$ & $N / A$ \\
\hline & no & 384 (84.2\%) & $231(76.2 \%)$ & \\
\hline
\end{tabular}

communication involving children using this video recording method was unlikely to alter nurse-child interactions.

\section{Ethical approval}

The study was independently reviewed by the Tayside Committee on Medical Research Ethics B, Scotland UK (approval number: 09/S1402/22). Participants (nursing staff and parents) were assured confidentiality and provided written consent. Approval from local educational authority was obtained.

\section{Participants}

Thirty-six schools across three Scottish NHS health boards (NHS Fife, NHS Forth Valley and NHS Tayside) were invited to participate over a period of 11 months between September 2009 and July 2010. These schools enrolled onto the Childsmile fluoride varnish application programme (Childsmile Nursery). The majority of the children (aged 3-5 years) were from a low social economic background. The school recruitment process involved an invitation letter addressed to the head teacher and a request was made to deliver a study information package, on behalf of the research team, to all eligible parents consented to the Childsmile programme. Sampling participating schools across three NHS health boards was purposive to allow heterogeneity in child behaviour and nurse encouragement styles in the interests of the findings being generalised to a wider 


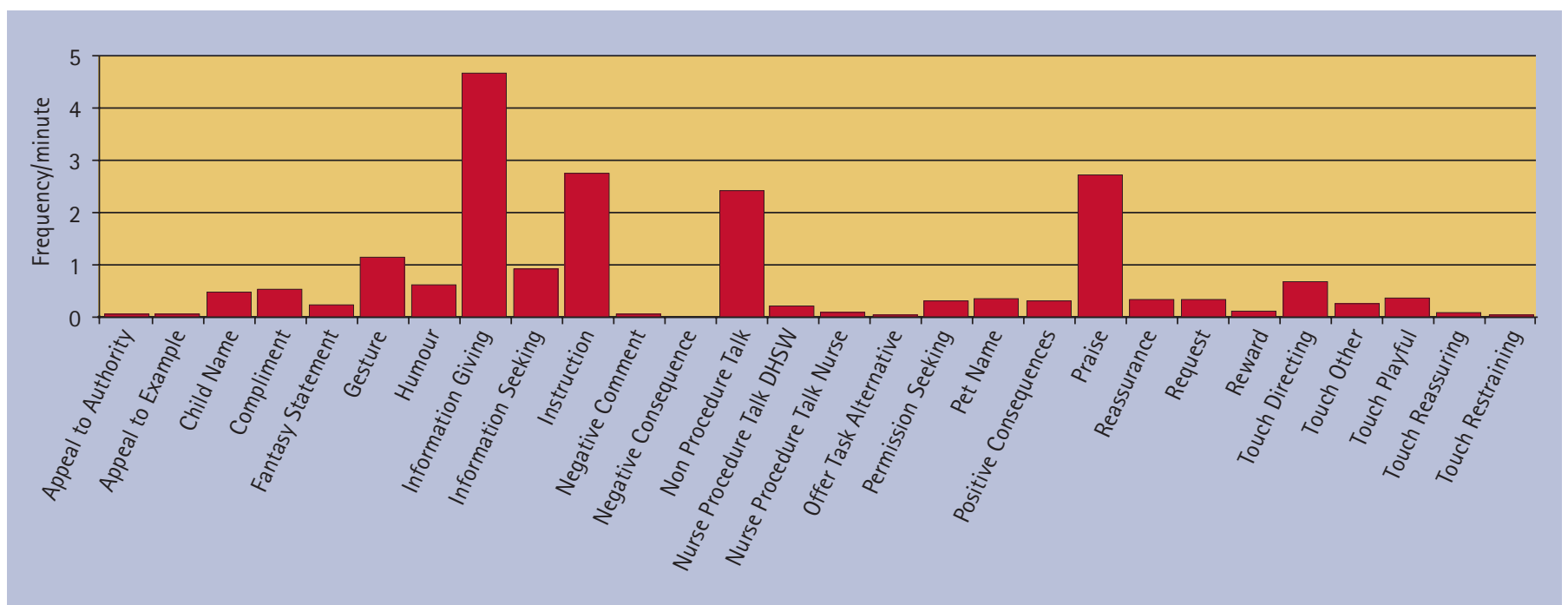

Fig. 1 Frequency of nurse-pair behaviours $(n=303)$

NB: 'silence' and 'all other non-verbal' behaviours excluded; nurse procedure talk DHSW = procedure talk between one nurse (nurses) and the dental health support worker; nurse procedure talk nurse = procedure talk between the two nurses; mean frequency of lead and support nurse combined behaviours adjusted to the duration of an interaction

population. School selection was, however, inevitably constrained by practical considerations such as school permission and diary constraints.

All 21 EDDNs from the three health board regions were invited to take part through an introductory meeting by the research team, to explain the study purpose and design. All parents of the 2,079 nurseryschool children from the sample schools received participation information, of whom 1,614 consented to the Childsmile programme were eligible to participate. These 1,614 parents were invited to consent their children to be video recorded receiving the fluoride varnish application.

\section{Coding scheme}

The St Andrews Behavioural Interaction Coding Scheme (SABICS) was specifically developed for this study and was used to code nurse-child interactive behaviours. ${ }^{13}$ Two members of the research team (YZ and GF) coded the video tapes overseen by GH. The SABICS contains 48 codes of which 29 are relating to nurse behaviours, including 22 verbal behaviours (for example, fantasy statement, information giving) and an additional seven non-verbal behaviours (for example, gesture, touch directing). All codes are given operational definitions with typical examples. An initial list of behaviours was developed following a close observation of video recorded interactions and key behaviours were drawn from relevant literature. The scheme was then refined through an iterative process of applying the scheme to new datasets. This coding scheme has demonstrated reasonable inter-coder reliability and evidence of discriminant validity. Furthermore, the SABICS has been purposively designed to enable both duration and frequency coding. Details of the coding scheme development, frequently asked questions and specific codes are available at http://www. st-andrews.ac.uk/sabics/.

\section{Analysis}

We define successful applications as those where all four quadrants of children's teeth are applied with the fluoride varnish application by the EDDNs. Whereas unsuccessful applications include both 'total refusal' (none of the child's teeth) and 'partial refusal' (one or several teeth from any part of the four tooth quadrants are applied with the fluoride varnish). We randomly selected (using matching criteria below) 303 video clips out of 456 recorded videos for coding and subsequent behavioural analysis. Coding selection criteria were based on:

- Unsuccessful applications (refusal and partial refusal)

- Those children whose parents returned a separate posted survey

- All initially anxious children

- Those children matched for gender, age, school and dental nurses for refusal, partial refusals, anxious and survey-returners.

Coding more extensive interactions, where anxious and unsuccessful children were involved, was expected to enhance our understanding of nurse encouragement strategies. In addition, significance testing using chi-square on the proportion of key characteristics (for example, problem teeth, gender) of coded and recorded children reassured us that the two groups were comparable.

The coding procedure was implemented through applying the SABICS on specialist behavioural coding software called The Observer $^{\circledast}$ XT system (Noldus Information Technology; http://www.noldus.com/ human-behaviour-research/products/ the-observer-xt). Analysis took place in three steps:

1. Mean frequency and duration for all 29 nurse-pair behaviours (lead and support nurse combined as a nurse pair) were calculated adjusting for the duration of an interaction

2. Correlation between mean frequency and duration of nurse-pair behaviour were calculated using the Pearson's correlation $r$ coefficient

3. Mean frequency and duration between successful and unsuccessful application sessions were compared using an independent group t test.

\section{RESULTS}

\section{Consent rates}

The consent rates for school and dental nurses were 97\% and 100\% respectively (Table 1). Of the 1,614 eligible parents, 509 gave their consent for their children 
to be video recorded at the fluoride varnish application. Of the 509 consented children, only 456 had their fluoride varnish application session video recorded. Reasons for missing recordings included absence ( $\mathrm{n}=37$ ) on the recording day, teacher advised non-participation ( $\mathrm{n}=15)$ and one withdrawal.

\section{Demographic information}

Table 2 summarises some key demographic information for recorded $(\mathrm{n}=456)$ and coded children $(n=303)$. The refusal rate of the recorded children was 7.5\% (34/456) and $10 \%(31 / 303)$ for the coded children.

\section{Frequency and duration of nurse-pair behaviour}

Figure 1 shows the mean frequency of nurse-pair behaviours for all 303 coded children adjusted to the duration of an interaction. The average duration of coded interaction was about three minutes (Mean $=3 \min 6 \mathrm{~s}, \mathrm{SD}=2$ min 17s). Results of correlation test show that all behaviour frequencies are significantly correlated with duration at a $\mathrm{p}<0.01$ level (see first column $n=303$ in Table 3 ). The equivalent mean duration bar chart is therefore not presented. For children who did not receive the fluoride application, it was found that the Pearson correlation value was noticeably low for 'gesture' $(r=0.148, p>0.05$, see third column $n=31$ in Table 3 ).

Of the 29 coded nurse behaviours, the most frequently used behaviours, and most extended in duration were (in frequency descending order): 'information giving' (17\%; for example, I am going to paint your teeth today), 'instruction' (6.5\%; for example, open your mouth wide please), 'praise' (5.5\%; for example, well done for being such a good climber [into the chair]) and 'non-procedural talk' (12.2\%; for example, how are you today at the nursery?). 'Gesture' (3.9\%; for example, demonstrating 'mouth open' for the child) and 'touch directing' (3.5\%; for example, lifting the child onto the treatment chair) were the 'top' two non-verbal behaviours on which nurses spent most time and used most often (Fig. 1). The percentage figures presented show behaviour duration in proportion to the length of an interaction. Summating the duration percentages of all the behaviours listed above demonstrates that nurses almost spend half (48.6\%) of

Table 3 Correlation between frequency and duration for nurse-pair behaviour

\begin{tabular}{|c|c|c|c|}
\hline \multirow[t]{2}{*}{ Nurse behaviour } & \multirow{2}{*}{$\begin{array}{l}\text { All children } \\
(n=303)\end{array}$} & \multicolumn{2}{|l|}{ Pearson's $r$ value } \\
\hline & & Successful $(n=272)$ & Unsuccessful $(n=31)$ \\
\hline Negative consequence & $0.973^{* *}$ & N/A & $0.972^{* *}$ \\
\hline Negative comment & $0.962^{* *}$ & $1.000^{* *}$ & $0.989^{* *}$ \\
\hline Appeal to example & $0.938^{* *}$ & $0.952^{* *}$ & $0.917^{* *}$ \\
\hline Humour & $0.920^{* *}$ & $0.926^{* *}$ & $0.924^{* *}$ \\
\hline Information seeking & $0.920^{* *}$ & $0.909^{* *}$ & $0.945^{* *}$ \\
\hline Reassurance & $0.908^{* *}$ & $0.915^{* *}$ & $0.896^{* *}$ \\
\hline Instruction & $0.906^{* *}$ & $0.904^{* *}$ & $0.896^{* *}$ \\
\hline Pet name & $0.887^{* *}$ & $0.885^{*}$ & $0.935^{* *}$ \\
\hline Positive consequence & $0.883^{* *}$ & $0.829^{* *}$ & $0.934^{* *}$ \\
\hline Touch restraining & $0.871^{* *}$ & $0.871^{* *}$ & $0.894^{* *}$ \\
\hline Reward & $0.867^{* *}$ & $0.842^{* *}$ & $0.959^{* *}$ \\
\hline Compliment & $0.864^{* *}$ & $0.847^{* *}$ & $0.973^{* *}$ \\
\hline Permission seeking & $0.859^{* *}$ & $0.857^{* *}$ & $0.833^{* *}$ \\
\hline Information giving & $0.842^{* *}$ & $0.834^{* *}$ & $0.896^{* *}$ \\
\hline Nurse procedure talk (other nurse) & $0.841^{* *}$ & $0.840^{* *}$ & $0.917^{* *}$ \\
\hline Praise & $0.819^{* *}$ & $0.804^{* *}$ & $0.809^{* *}$ \\
\hline Touch playful & $0.818^{* *}$ & $0.838^{* *}$ & $0.862^{* *}$ \\
\hline Appeal to authority & $0.813^{* *}$ & $0.825^{* *}$ & $0.780^{* *}$ \\
\hline Child name & $0.805^{* *}$ & $0.797^{* *}$ & $0.890^{* *}$ \\
\hline Touch other & $0.802^{* *}$ & $0.797^{* *}$ & $0.861^{* *}$ \\
\hline Nurse procedure talk (total) & $0.789^{* *}$ & $0.788^{* *}$ & $0.700^{* *}$ \\
\hline Offer task alternative & $0.742^{* *}$ & $0.963^{* *}$ & $0.636^{* *}$ \\
\hline Nurse procedure talk (DHSW) & $0.718^{* *}$ & $0.716^{* *}$ & $1.000^{* *}$ \\
\hline Touch directing & $0.684^{* *}$ & $0.658^{* *}$ & $0.884^{* *}$ \\
\hline Non procedure talk & $0.650^{* *}$ & $0.661^{* *}$ & $0.584^{* *}$ \\
\hline Fantasy & $0.599^{* *}$ & $0.602^{* *}$ & $0.543^{* *}$ \\
\hline Gesture & $0.502^{* *}$ & $0.593^{* *}$ & 0.148 \\
\hline Touch reassurance & $0.47^{* *}$ & $0.504^{* *}$ & $0.333^{* *}$ \\
\hline Request & $0.376^{* *}$ & $0.38^{* *}$ & $0.315^{*}$ \\
\hline
\end{tabular}

the interaction time on average engaging with the child.

\section{Comparison of nurse behaviour between successful and unsuccessful applications}

Figures 2 and 3 show that differences in frequency and duration of nurse behaviours between successful and unsuccessful applications were consistent. Regarding differences in behaviour frequency, independent t test results show (Table 4) that, during unsuccessful application sessions (refusals), nurse pairs used more frequently the following behaviours: "permission seeking'(for example, is it OK if I count your teeth?), 'information seeking'(for example, do you go to the dentist?), 'offer task alternative'(for example, just count the teeth today) and 'reassurance'(for example, it's easy-peasy). Whereas in successful sessions, 'praise', 'instruction' and 'procedure talks' between nurses and the dental health support worker (DHSW), occurred more frequently. The DHSW had an administrative role in the procedure 


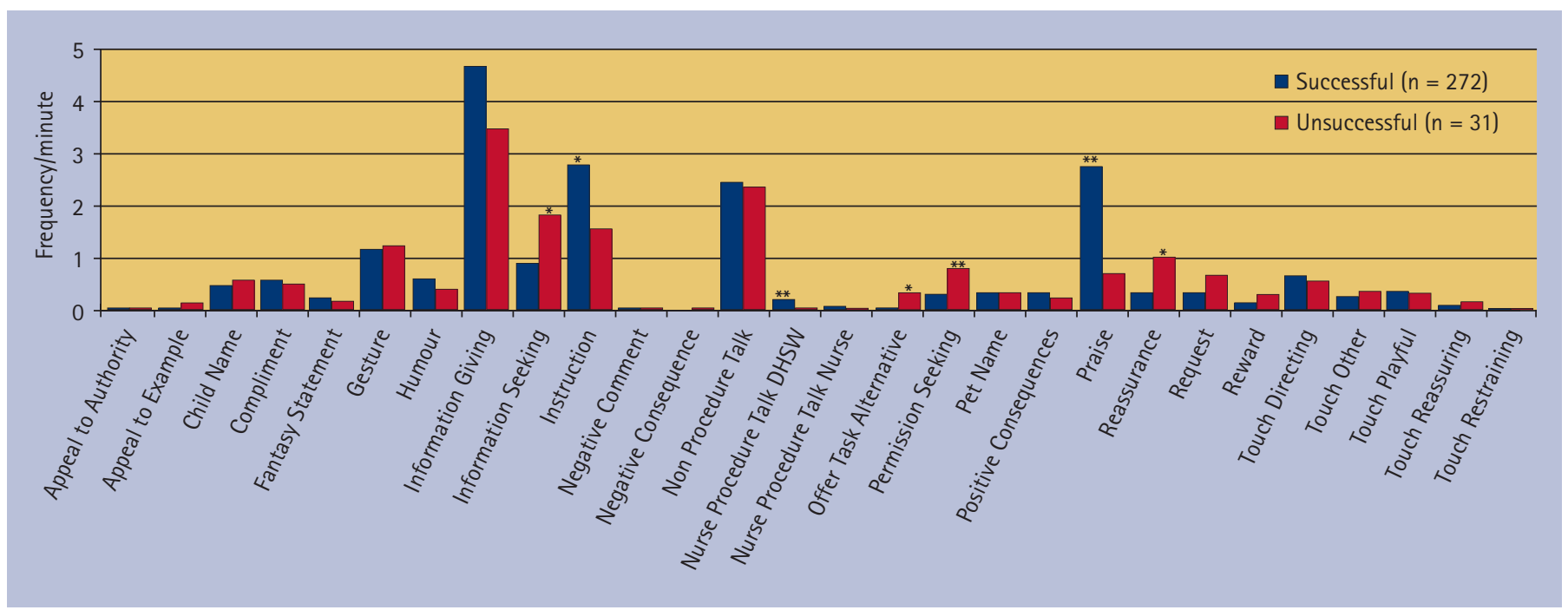

Fig. 2 Comparison in the frequency of nurse-pair behaviours between successful and unsuccessful applications

NB: 'silence' and 'all other non-verbal' behaviours excluded; nurse procedure talk DHSW = procedure talk between one nurse (nurses) and the dental health support worker; nurse procedure talk nurse = procedure talk between the two nurses; mean frequency of lead and support nurse combined behaviours adjusted to the duration of an interaction; ${ }^{*} p<0.01 ;{ }^{* *} p<0.001$

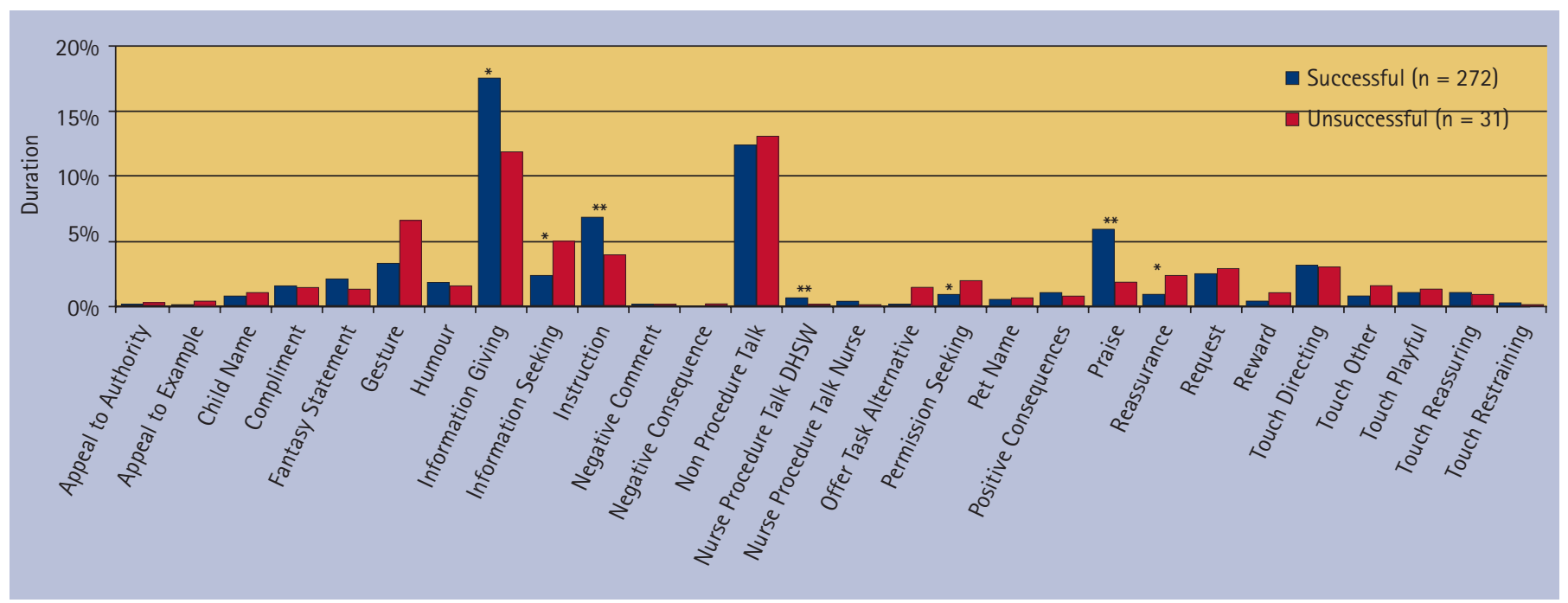

Fig. 3 Comparison in the duration of nurse-pair behaviours between successful and unsuccessful applications

NB: 'silence' and 'all other non-verbal' behaviours excluded; mean duration of lead and support nurse combined behaviours in proportion to the duration of an interaction; ${ }^{*} p<0.01 ; *$ * $p<0.001$

in identifying children and filing the application record.

Regarding duration differences, t test results (Table 5) show that nurse pairs also seemed to spend longer time on 'permission seeking', 'information-seeking' and 'reassurance' with children who refused. Whereas with children who received the application, time nurses spent praising, giving treatment-related information and instruction and talking to dental health support workers about procedures were significantly longer.

\section{DISCUSSION}

The EDDNs have now formed a new category of dental workers who are registered to conduct some specific dental procedures independently. This study is the first to provide a detailed profile of the behaviour of the EDDNs in their direct engagement with children in a community setting. No incidents occurred in any of the 303 recordings where a nurse threatened or placed undue pressure on a child as a result of child disruptive behaviour. We extended our observational inquiry to all 456 recordings and confirmed the finding that no adverse incidents occurred. In fact, the code 'punishment' was removed from the initial pilot version of SABICS because it was not observed in the development phase ( $n=54$ children). In addition, those behaviours that might be constituted to apply unfavourable influence (such as 'appeal to authority', 'negative comment' and 'negative consequence') were very rarely used. The EDDNs were spending nearly half of their interaction time engaging children and encouraging acceptance of the application. These findings have confirmed our field observations, and addressed our second research question that the EDDNs acted professionally and demonstrated considerable compassion for young children.

Our study has the advantage of recording both frequency and duration of behaviours as both indicators are not always highly related. ${ }^{14}$ We found a highly significant positive correlation between frequency and 
duration for almost all behaviours except that, in unsuccessful application sessions, the correlation for 'gesture' was low. The research team observed that, in unsuccessful sessions, where uncooperative children are usually involved, nurses often demonstrated the behaviour 'mouth open' (coded as 'gesture') for extensive periods of time. It seems that some elements of 'tell-showdo' technique were also well integrated into their extended skills, ${ }^{15}$ particularly in persuading uncooperative children.

To answer the third and fourth research questions, our findings suggest that the EDDNs do seem to demonstrate a different behavioural profile between successful and unsuccessful application sessions. In unsuccessful sessions, nurses tended to ask children more questions. These were to enquire about the procedure or to seek permission for them to conduct procedure. We are uncertain at this stage whether these question-seeking-oriented behaviours alert children, or nurses are responding to the child and hence triggering the nurses' behavioural responses. Behavioural sequential analysis is an important technique in the next stage of our research to examine the contemporaneous order of effects of specific behaviours. ${ }^{16}$

We also found, with unsuccessful sessions, 'offering task alternative' and 'reassurance' were two other distinctive strategies employed by the nurses. From video and field observation, we noticed that these attempts at encouraging fluoride application appeared to be a consequence of uncooperative behaviour exhibited by the child. Although this type of empathic working style was found to have a positive effect in reducing fear-related behaviours in children, ${ }^{17,18}$ in this context of a community setting with a preventive agent the typical recommended strategy was unsuccessful.

'Praise', 'instruction', 'information-giving' and 'nurse-procedure talk' were behaviours observed more frequently and for a longer duration in successful applications. There is some evidence in the literature suggesting that giving clear instructions about the next stage in a clinical procedure, positive reinforcement following specific child behaviour, dental-orientated communication between dentist and assistant improve child cooperation. ${ }^{10}$ We speculate that this type of behaviour encourages acceptability, but caution is warranted not to confuse correlational and causal relationships.

Table 4 Comparison of frequency of nurse-pair behaviours between successful and unsuccessful applications

\begin{tabular}{l|l|l|l|l} 
& \multicolumn{2}{l}{ Mean (SD) } & \multicolumn{2}{l}{ Difference } \\
\cline { 2 - 5 } & $\begin{array}{l}\text { Successful } \\
(n=272)\end{array}$ & $\begin{array}{l}\text { Unsuccessful } \\
(n=31)\end{array}$ & $t$ & $p$ value \\
\hline Permission seeking & $0.30(0.62)$ & $0.80(0.64)$ & 4.17 & 0.000 \\
\hline Offer task alternative & $0.02(0.10)$ & $0.33(0.49)$ & 3.53 & 0.001 \\
\hline Information seeking & $0.89(1.20)$ & $1.80(1.80)$ & 2.78 & 0.009 \\
\hline Reassurance & $0.34(0.84)$ & $1.00(1.30)$ & 2.72 & 0.010 \\
\hline Praise & $2.70(1.90)$ & $0.68(0.89)$ & 10.00 & 0.000 \\
\hline Nurse procedure talk DHSW & $0.20(0.36)$ & $0.03(0.15)$ & 4.90 & 0.000 \\
\hline Instruction & $2.80(2.10)$ & $1.50(1.50)$ & 3.08 & 0.002 \\
\hline NB: Only behaviours with differences $p \leq 0.01$ reported; DHSW = dental health support worker & & \\
\hline
\end{tabular}

Table 5 Comparison of duration of nurse-pair behaviours between successful and unsuccessful applications

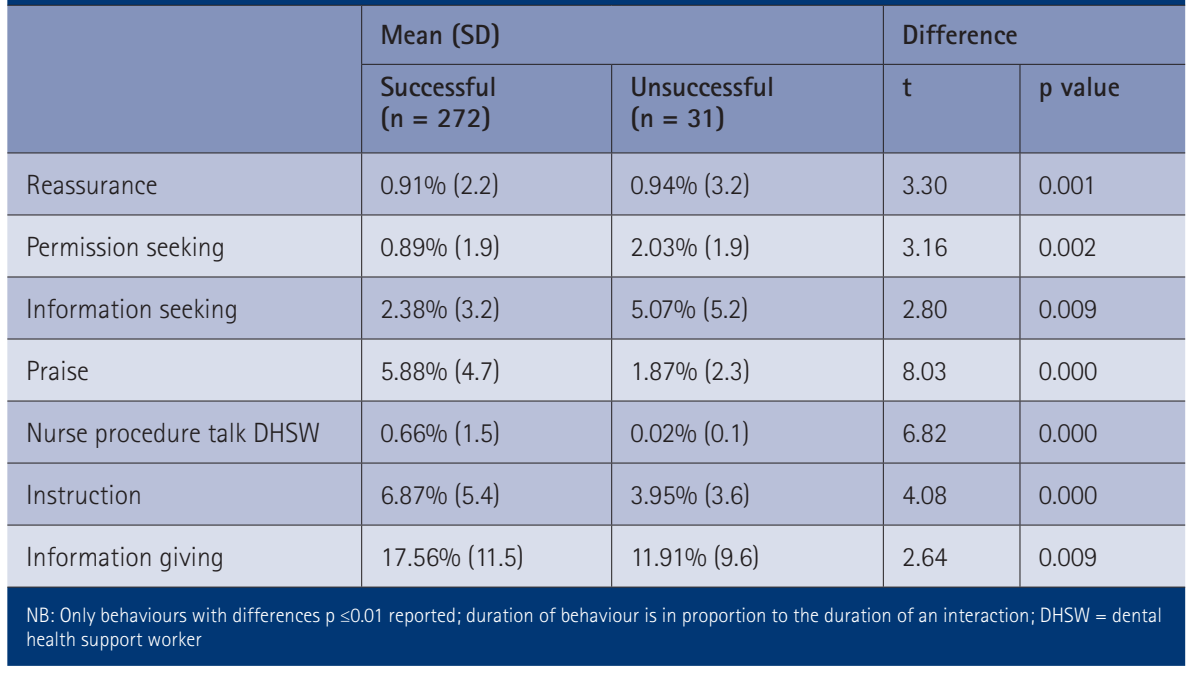

This study is the only observational survey of EDDNs conducted using a validated behavioural coding scheme. The authors are aware of some inevitable limitations. The representativeness of children in the final coded sample is questionable as the consent rate from parents was relatively low. Neuman ${ }^{19}$ reports that the return rate for mail survey method usually falls between 10\% and 50\%, a consent rate of $32 \%$ can be therefore considered acceptable, given that the child consenting process was conducted through posting information to parents. The presence of a video camera to capture the application procedure appeared not to influence the nurses or children as previously mentioned. However, this probably cannot be completely excluded. This report only presents a descriptive profile of nurse behaviour. No assumptions were made about causation. Additional analysis is warranted to look at predictors of acceptance, for example whether the child's previous experience of application influences nurse behaviour and the application outcome.

\section{CONCLUSION}

The behavioural profile of the EDDNs suggests that they acted in a professional manner when performing their extended duties with preschool children in a Childsmile fluoride varnish application intervention. The EDDNs do seem to behave differently between successful and unsuccessful sessions. These differences point to a focus on sequential analysis approaches in the next stage, to explore the chains and linkages between specific behaviours and their effects on delivery outcomes. 


\section{DISCLAIMER}

This work was undertaken by University of St Andrews, which received funding from Childsmile; the views expressed in this publication are those of the authors and not necessarily those of the funders.

This study was supported by the NHS Fife in the pilot stage and the Scottish Government, via the Childsmile Evaluation Board, who provided funding for the main study. We also thank all nursery schools, dental nurses, parents and children who participated in this study.

1. O'Keefe E. Fluoride varnish may be effective in preschoolers. Evid Based Dent 2011; 12: 41-42.

2. Macpherson L M, Ball G E, Brewster L et al. Childsmile: the national child oral health improvement programme in Scotland. Part 1: establishment and development. Br Dent J 2010; 209: 73-78.

3. Turner S, Brewster L, Kidd J et al. Childsmile: the national child oral health improvement programme in Scotland. Part 2: monitoring and delivery. Br Dent J 2010; 209: 79-83.

4. General Dental Council. Scope of practice. London: GDC, 2009.
5. NHS Primary Care Commissioning. The use of fluoride varnish by dental nurses to control caries. London, Department of Health, 2009.

6. Jones $C M$, Walker $A$. The role of extended duties dental nurses in applying fluoride varnish for the prevention and control of dental caries. Dent Update 2010; 37: 549-552, 554.

7. Carter E, Parker M, Gallagher J E. The impact of fluoride application training: survey of trained dental nurses from King's College Hospital NHS Trust. Br Dent J 2012: 212: E15.

8. Childsmile. Childsmile national headline data. Scotland: Childsmile, 2011. Online data available at http://www.child-smile.org.uk/documents/5225. aspx. (accessed December 2012).

9. Stewart M A. Effective physician-patient communication and health outcomes: a review. CMAJ 1995: 152: 1423-1433.

10. Zhou Y, Cameron E, Forbes G, Humphris G. Systematic review of the effect of dental staff behaviour on child dental patient anxiety and behaviour. Patient Educ Couns 2011; 85: 4-13.

11. Penner $L A$, Orom $H$, Albrecht $T L$, Franks M M, Foster TS, Ruckdeschel J C. Camera-related behaviours during video recorded medical interactions. J Nonverbal Behav 2007; 3: 99-117.

12. Zhou $Y$, Forbes $G M$, Humphris $G$. Camera-related behaviours of female dental nurses and nursery school children during fluoride application interactions in nursery school settings. Int J Paediatr Dent 2010; 20: 374-381.

13. Zhou Y, Cameron E, Forbes $G$, Humphris $G$ Development of a novel coding scheme (SABICS) to record nurse-child interactive behaviours in a community dental preventive intervention. Patient Educ Couns 2012; 88: 268-276.

14. Dunbar R I M. Some aspects of research design and their implications in the observational study of behaviour. Behaviour 1976; 58: 78-98.

15. Eaton J J, McTigue D J, Fields H W Jr, Beck M. Attitudes of contemporary parents toward behaviour management techniques used in pediatric dentistry. Pediatr Dent 2005; 27: 107-113.

16. Bakeman $R$, Gottman J M. Observing interaction: an introduction to sequential analysis. 2 nd ed. New York: Cambridge University Press, 1997

17. Sarnat $H$, Arad $P$, Hanauer D, Shohami E. Communication strategies used during pediatric dental treatment: a pilot study. Pediatr Dent 2001; 23: 337-342.

18. Stave J A. The relationship between empathic dentist behaviour and children's cooperation. J Dent Educ 1983; 47: 555-557.

19. Neuman W L. Social research methods: qualitative and quantitative approaches. Boston: Allyn and Bacon, 1991. 